\title{
Verzeichnis der Abbildungen und Tabellen
}

\section{Abbildungen}

Grafik 1: Die Konstitution und Entwicklung von Pfaden - 39

Grafik 2: Reactive Sequence und Conjuncture nach Mahoney -42

Grafik 3: Landzuweisungen durch den US-Kongress in Acres, 1850-1871 — 182

Grafik 4: Exporte agrarischer Rohstoffe 1860-1920 197

\section{Tabellen}

Tabelle 1: Landschenkungen des Bundes an Eisenbahnen in Acres — 183

Tabelle 2: Beschäftigungsstruktur der Textilindustrie im Norden und Süden im Vergleich 193

Tabelle 3: Holzunternehmen im Süden — 197

Tabelle 4: Durchschnittliche Zolltarife der Vereinigten Staaten — 207

Tabelle 5: Staatliche Landsubventionen für die Union Pacific — 269

Tabelle 6: Vergleich des Absatzes von lebendigem Vieh mit Kühlfleisch — 285

Tabelle 7: Gründungen von Konzernen und Insolvenzrate — 291

Tabelle 8: Wahlbeteiligung — 304

Tabelle 9: Durchschnittliche Jahreslöhne der Industriearbeiter — 322

Tabelle 10: Großhandelspreise für Weizen und Baumwolle in Dollar — 387

Tabelle 11: Streikaktivitäten der 1880er Jahre — 393

Tabelle 12: Geschätzte Arbeitslosigkeit in Prozent — 409 
